\title{
Synthesis and Characterization of Metal Sulfides Nanoparticles/Poly(methyl methacrylate) Nanocomposites
}

\author{
Peter A. Ajibade and Johannes Z. Mbese \\ Department of Chemistry, University of Fort Hare, Private Bag X1314, Alice 5700, South Africa \\ Correspondence should be addressed to Peter A. Ajibade; pajibade@ufh.ac.za
}

Received 28 April 2014; Revised 25 July 2014; Accepted 25 July 2014; Published 7 September 2014

Academic Editor: Yulin Deng

Copyright ( 2014 P. A. Ajibade and J. Z. Mbese. This is an open access article distributed under the Creative Commons Attribution License, which permits unrestricted use, distribution, and reproduction in any medium, provided the original work is properly cited.

\begin{abstract}
Metal sulfides nanoparticles in poly(methyl methacrylate) matrices were prepared and characterized by infrared spectroscopy, thermogravimetric analysis, powder X-ray diffraction, scanning electron microscope (SEM), and transmission electron microscope (TEM). The FTIR confirms the dispersion of the nanoparticles in PMMA matrices with the $\mathrm{C}=\mathrm{O}$ and C-O-C bonds of the PMMA shifting slightly which may be attributed to the interactions between the nanoparticles and PMMA. The ZnS nanoparticles in PMMA have average crystallite sizes of 4-7 nm while the CdS has particle size of $10 \mathrm{~nm}$ and $\mathrm{HgS}$ has crystallite sizes of 8-20 nm. The increasing order of particle sizes as calculated from the XRD is $\mathrm{ZnS} / \mathrm{PMMA}<\mathrm{HgS} / \mathrm{PMMA}<\mathrm{CdS} / \mathrm{PMMA}$ and ranges from 1.02 to $1.35 \mathrm{~nm}$. These calculated particle sizes are smaller than the values obtained from TEM.
\end{abstract}

\section{Introduction}

In recent years, there have been reports of the incorporation of semiconductor metal sulfide nanoparticles into polymers by chemical methods and the polymer matrices serve to protect the particle surfaces [1]. Among the broad variety of available polymers, poly(methyl methacrylate) or PMMA is one of the most widely studied due to its outstanding mechanical and chemicophysical properties $[2,3]$. The choice of polymers depends on the mechanical, thermal, electrical, optical, and magnetic properties of the polymers. However, other properties such as hydrophobic/hydrophilic balance, chemical stability, biocompatibility, optoelectronic properties, and chemical functionalities have also been considered [4]. The PMMA has a polar ester group $-\mathrm{COOCH}_{3}$ with a dipole moment of 1.6 Debye and dielectric constant of 3.4 [5]. Its wide applications in many technological and productive fields take advantage of the unique combination of excellence [1-9]. However, PMMA has limitations such as its thermal instability and inability to filter ultraviolet light which has restricted its universal usage. These drawbacks may be overcome by incorporation of semiconductor nanoparticles into the polymer matrices to form nanocomposites [10-12].
Recent researches have focused on the synthesis, characterization, and optical properties of metal sulfides/polymer nanocomposites such as ZnS/PMMA and CdS/PMMA nanocomposites [13]. The incorporation of metal sulfide nanocrystals into polymer matrices has been accomplished via direct blending $[14,15]$, in situ synthesis of nanoparticles within polymer media $[16,17]$, and surface modification of nanoparticles with monomers followed by polymerization from nanoparticle surface and grafting of preformed functionalized polymers to nanoparticles [18]. The major goal for synthesis of nanocomposites is to obtain compounds that are optically clear and thermally stable with good mechanical properties [19]. However, shape control has been much more difficult to achieve; hence, exploration of novel method for the preparation of differently shaped nanoparticles in polymer matrix is challenging area of research [20]. In this study, we present the preparation of $\mathrm{ZnS}, \mathrm{CdS}$, and $\mathrm{HgS}$ nanoparticles in PMMA matrices. The nanocomposites were studied by Fourier transform infrared spectroscopy (FT-IR), thermogravimetric analyses (TGA), X-ray diffraction (XRD), scanning electron microscopy (SEM), energy dispersive Xray analysis (EDX), and transmission electron microscopy (TEM). 


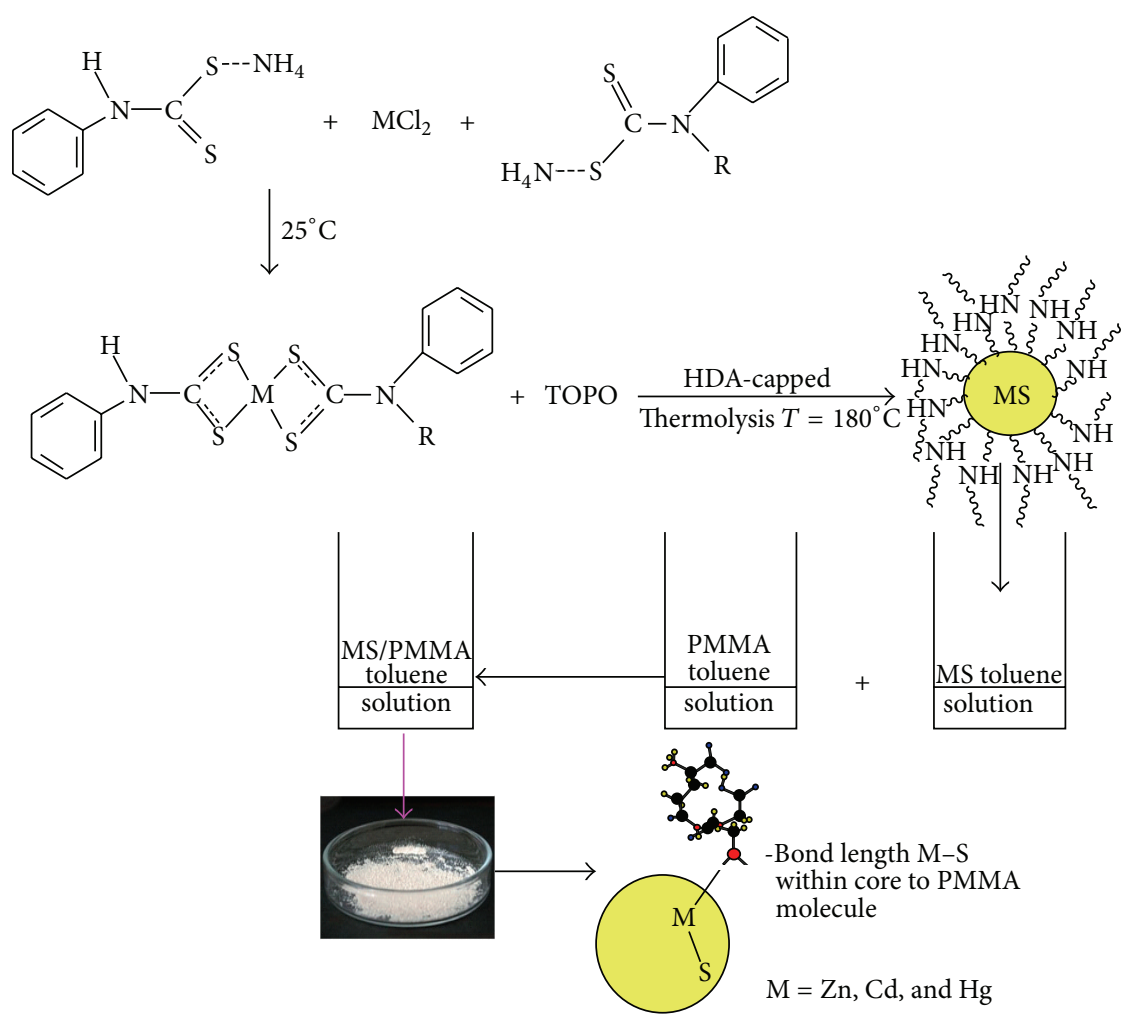

SCHeme 1: Steps for the preparation of the metal sulfides/PMMA nanocomposites.

\section{Results and Discussion}

2.1. Synthesis. The procedure for the synthesis of the nanocomposites is shown in Scheme 1. Yellow to white nanocomposites of $\mathrm{ZnS} / \mathrm{PMMA}$, CdS/PMMA, and HgS/PMMA were obtained in a good yield of $85-95 \%$ with thickness of $0.1-$ $0.2 \mathrm{~mm}$.

2.2. Infrared Spectra. The infrared spectra of PMMA, ZnS/PMMA, CdS/PMMA, and HgS/PMMAnanocomposites are shown in Figure 1. In the PMMA spectrum, the peak assigned to the $\mathrm{C}-\mathrm{H}$ stretching vibration occurred at $2977 \mathrm{~cm}^{-1}$. The strong peak at $1730 \mathrm{~cm}^{-1}$ is assigned to $v \mathrm{C}=\mathrm{O}$ stretching vibration. The peaks at 1157,1199 , and $1265 \mathrm{~cm}^{-1}$ correspond to $\mathrm{C}-\mathrm{O}-\mathrm{C}$ stretching and deformation vibrations. The peaks observed at $999 \mathrm{~cm}^{-1}$ and $858 \mathrm{~cm}^{-1}$ are due to C$\mathrm{H}$ bending vibrations and the peak at $746 \mathrm{~cm}^{-1}$ is attributed to the vibrations of the polymer chains $[11,21]$.

The FTIR spectra of ZnS/PMMA, CdS/PMMA, and $\mathrm{HgS} / \mathrm{PMMA}$ nanocomposites were compared to free PMMA spectra. The comparison gave almost identical feature, except the absence of peak around $1640 \mathrm{~cm}^{-1}$, due to the double bond of MMA monomer [22]. This also indicates the homogeneity of nanocomposites solution since only 3\% weight of metal sulfide nanoparticles was used. These results confirmed that the dispersion of metal sulfide nanoparticles into PMMA was successful.

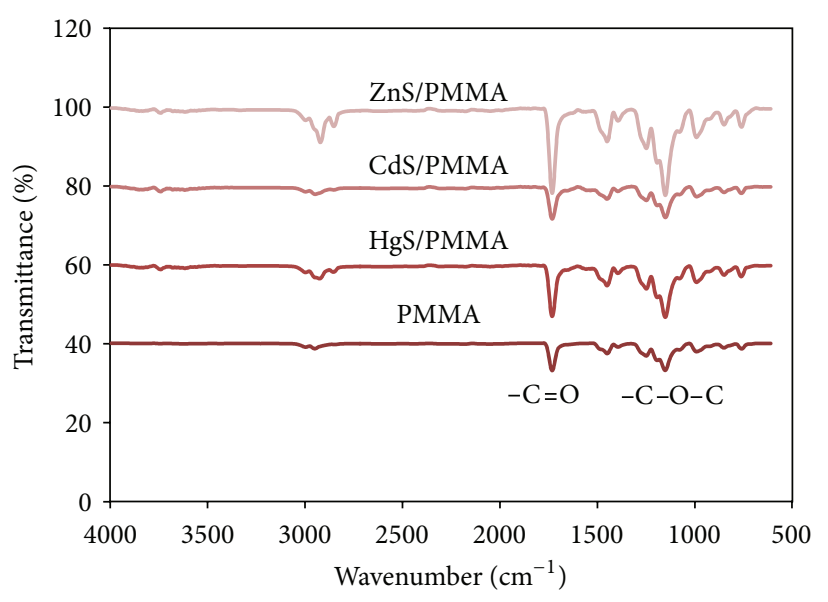

FIGURE 1: The FTIR spectra of PMMA and its metal sulfides/PMMA nanocomposites.

2.3. X-Ray Diffraction Patterns. The XRD patterns of ZnS/PMMA, CdS/PMMA, and HgS/PMMA nanocomposites were carefully studied and compared with that of pure PMMA as shown in Figure 2. Shallow peaks were observed for pure PMMA matrix, suggesting the absence of nanoparticles. However, broad diffraction peaks appeared in the case of the $\mathrm{ZnS}$ embedded in PMMA matrix. The peak broadening in the XRD patterns clearly indicates the formation of $\mathrm{ZnS}$ nanoparticles of small size $[23,24]$. Three characteristic 


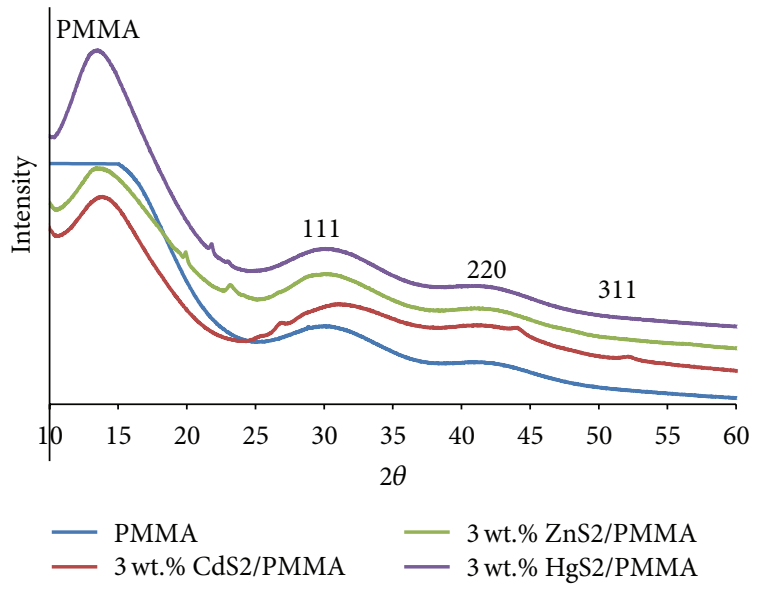

FIGURE 2: XRD patterns of pure PMMA, ZnS/PMMA, CdS/PMMA, and HgS/PMMA nanocomposites.

peaks were observed for ZnS/PMMA nanocomposites corresponding to the lattice planes of (111), (220), and (311) that matched well with the cubic $\mathrm{ZnS}$ structure (JCPDS number 05-0566) [25]. It is worth noting that the peak percentage and intensity of inorganic phase in a nanocomposite sample are low but the signal corresponding to the most abundant crystallographic planes of PMMA matrix can be detected at diffraction angle $2 \theta=10-20^{\circ}[24,26-28]$.

The average particle size has been calculated from X-ray diffraction study using the Debye Scherer formula [29]. The calculated size is found to be $1.02 \mathrm{~nm}$, indicating the presence of nanosized ZnS nanoparticles. The XRD pattern (Figure 2) obtained for CdS2/PMMA nanocomposites corresponded to pure cubic CdS when compared with the standard reference (JCPDS 03-065-2887) [30]. Three peaks with $2 \theta$ values of $29.4,43.3$, and 52.3 appeared in the spectrum of the sample and may be assigned to the (111), (220), and (311) Miller indices. This confirms the presence of CdS nanoparticles incorporated into PMMA matrix because the pure PMMA pattern does not clearly display all the peaks observed in CdS/PMMA nanocomposites. The very broad XRD peak at a low diffraction angle, around $2 \theta=13.5^{\circ}$, indicates amorphous PMMA [31]. The average crystallite size calculated using the Debye Scherer equation was $1.35 \mathrm{~nm}$.

The phase composition of as-synthesized HgS/PMMA nanocomposites shows three broad characteristic peaks for HgS/PMMA nanocomposites $\left(2 \theta=29.7^{\circ}, 41.5^{\circ}\right.$, and $\left.52.5^{\circ}\right)$ corresponding to the Miller indices (111), (220), and (311), respectively [32-34]. The broadness of the XRD peaks could be due to the homogeneity of the prepared nanocomposites solution. The broadening of the diffraction peaks allows an approximate evaluation of crystallite size by the Scherer formula and the distribution of peak intensities may give also an idea of nanoparticle shape [24]. The diffraction peak due to PMMA in the HgS/PMMA sample is at $2 \theta=13.5^{\circ}$. The crystallite size as calculated from Scherer equation was found to be $1.07 \mathrm{~nm}$. The increasing order of particle sizes is $\mathrm{ZnS} / \mathrm{PMMA}<\mathrm{HgS} / \mathrm{PMMA}<\mathrm{CdS} / \mathrm{PMMA}$ ranging from 1.02 to $1.35 \mathrm{~nm}$. These calculated particle sizes are smaller
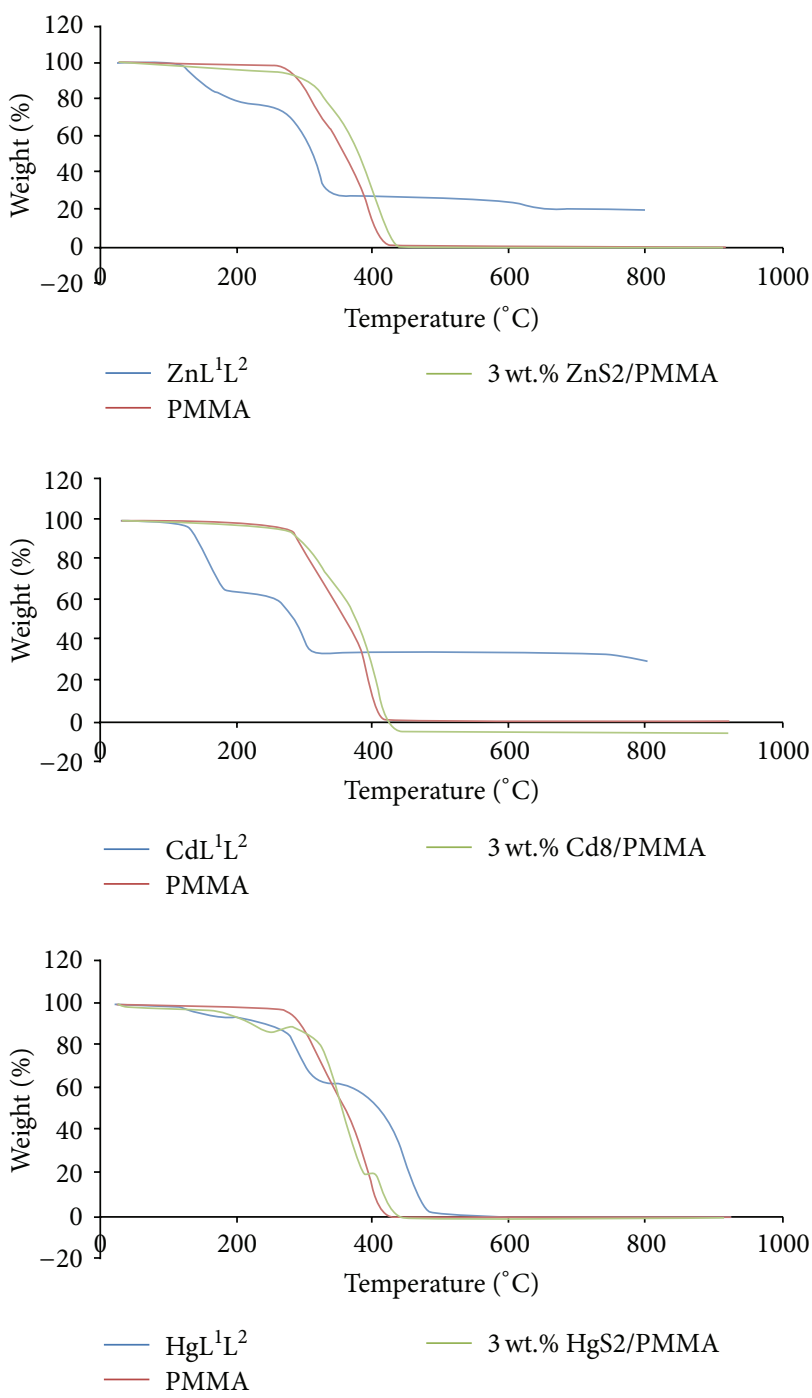

FIgURE 3: TGA curves for $\mathrm{ML}^{1} \mathrm{~L}^{2}$ precursor complex, pure PMMA, and their MS2/PMMA nanocomposites. $\mathrm{M}=\mathrm{Zn}, \mathrm{Cd}$, and $\mathrm{Hg}$.

than those particle sizes obtained from electron microscopy, suggesting that estimating the particles using the XRD alone is not enough because of the presence of materials not directly estimated via XRD studies.

2.4. Thermogravimetric Analyses of the Metal Sulfides/PMMA Nanocomposites. The TGA decomposition patterns of metal sulfide/PMMA (ZnS/PMMA, CdS/PMMA, and $\mathrm{HgS} /$ PMMA) nanocomposites were studied and carefully compared with the decomposition curves of the PMMA polymer and their respective precursor complexes in Figure 3.

The main degradation step of ZnS/PMMA nanocomposites occurs at $265-425^{\circ} \mathrm{C}$. The TGA curves for free PMMA show one major decomposition step at $260-420^{\circ} \mathrm{C}$, owing to the decomposition of PMMA matrix [21]. However, the thermal stability of the ZnS/PMMA nanocomposites is enhanced compared to the pure PMMA, which may be due to partially altered molecular mobility of the polymer chains due to their 


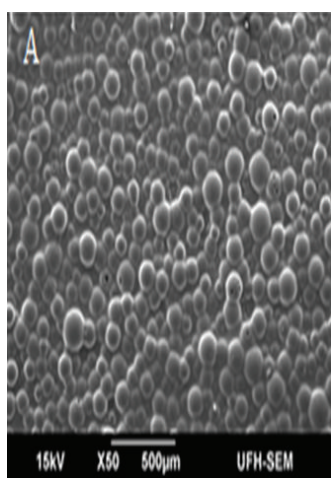

(A)

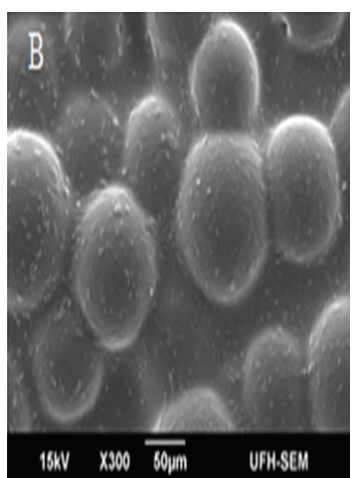

(B)

ZnS2/PMMA(1)_pt1

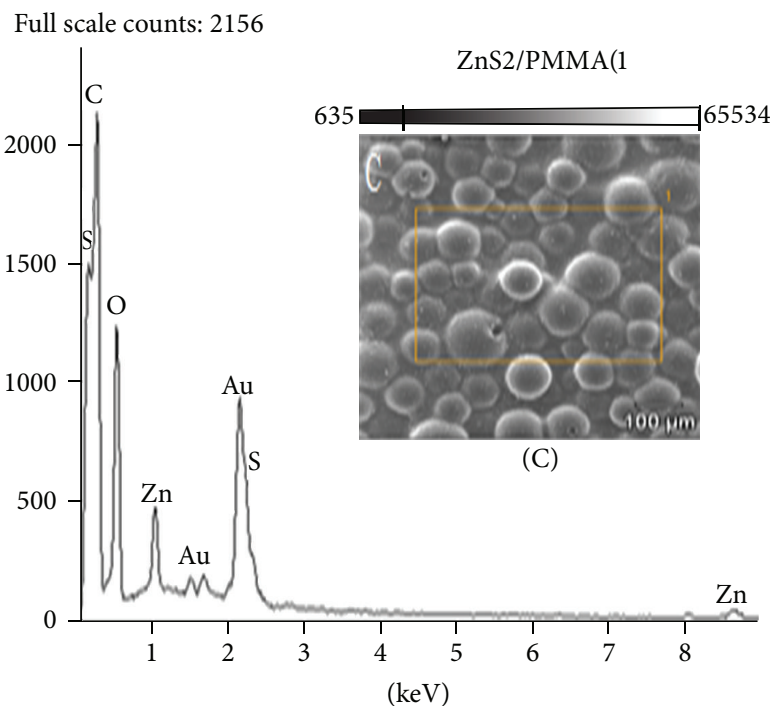

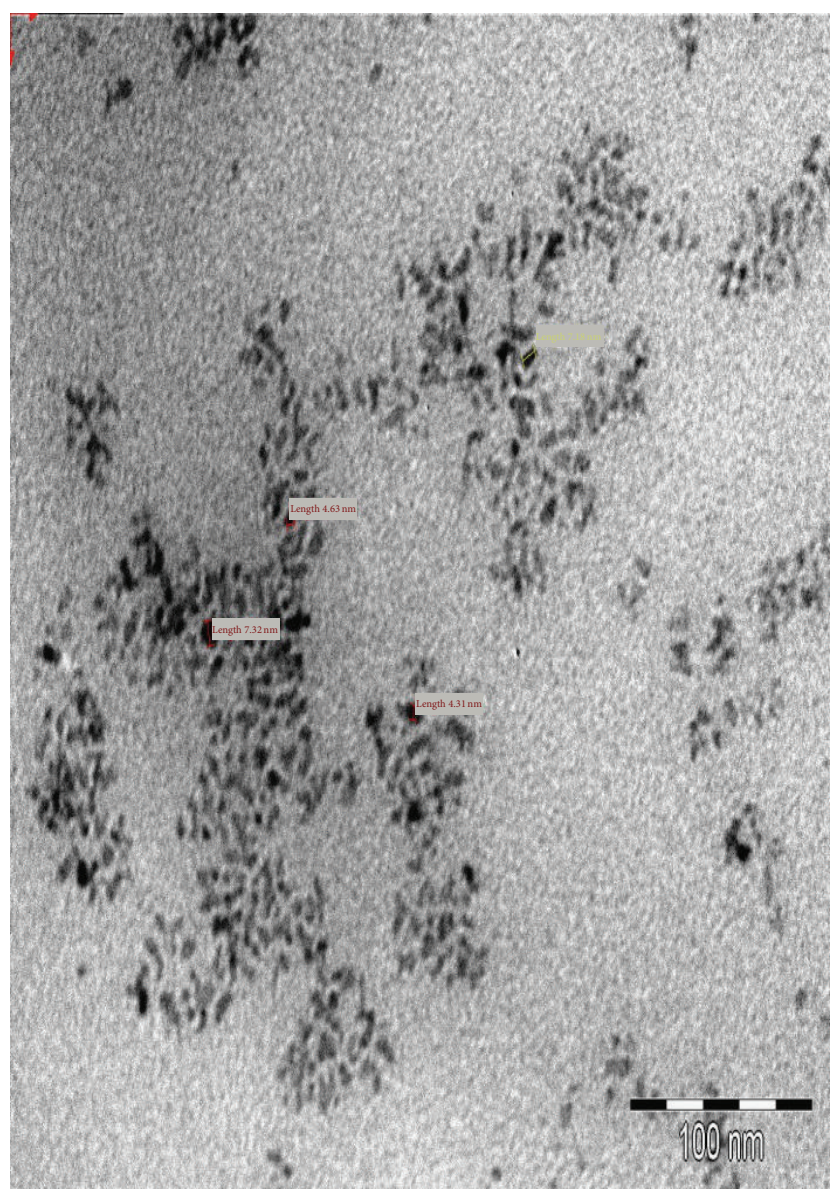

(D)

Figure 4: (A) and (B) are SEM micrograph of ZnS2/PMMA nanocomposites at different magnification; (C) EDX spectrum of the sample; (D) TEM micrograph.

adsorption on the surface of the nanoparticles because of the amount of $\mathrm{ZnS}$ nanoparticles embedded into PMMA matrix [35]. The major decomposition step for CdS/PMMA nanocomposite occurs at about $270-430^{\circ} \mathrm{C}$. These results depict that the thermal stability of CdS/PMMA nanocomposites is higher than that of its PMMA matrix showing strong interactions between the CdS nanoparticles and the PMMA polymer matrix. The TGA curve of the nanocomposites also indicates the presence of residue ascribed to the presence of the CdS2 nanoparticles dispersed in PMMA matrix. The TGA decomposition curves for HgS/PMMA nanocomposites indicate that the thermal stability for HgS/PMMA nanocomposites is similar to that of the PMMA matrix except that the nanocomposites started to decompose at a temperature below $100^{\circ} \mathrm{C}$, accompanied with a weight loss of about $10 \%$.

When ZnS/PMMA, CdS2/PMMA, and HgS/PMMA nanocomposites are compared to their respective precursor complexes used in the synthesis of the metal sulfide nanoparticles, it could be noted that the nanocomposites are more thermally stable than their precursor complexes at temperatures below $400^{\circ} \mathrm{C}$. This confirms strong interaction between metal sulfide nanoparticles and the polymer matrix.
The precursor complexes seem to be more stable after $400^{\circ} \mathrm{C}$ due to the presence of metal sulfide nanoparticles residue although the mercury precursor complex shows the process of volatilization of the sample.

2.5. SEM and EDX of the Metal Sulfides Nanocomposites. The SEM micrograph of ZnS/PMMA (Figures 4(A) and 4(B)) showed regular well spherical morphology of nanocomposites indicating that $\mathrm{ZnS}$ nanocomposites were hosted within PMMA matrix. EDX spectrum of ZnS/PMMA nanocomposites reveals that the prepared nanocomposites are mainly composed of zinc and sulfur atoms within the scan area, confirming the presence of $\mathrm{ZnS}$ nanoparticles in PMMA matrix. Other traces of elements like carbon and oxygen are observed possibly due to the use of carbon tape and retained solvent after the deposition step [25]. The intense Au peaks are due to gold and palladium coating which was used to overcome charging of samples.

Figures 5(A) and 5(B) show the CdS2/PMMA of the nanocomposites and the EDX spectrum is displayed in Figure 5(C). In these images, it could be seen that there is existence of CdS particles which are homogeneously dispersed 


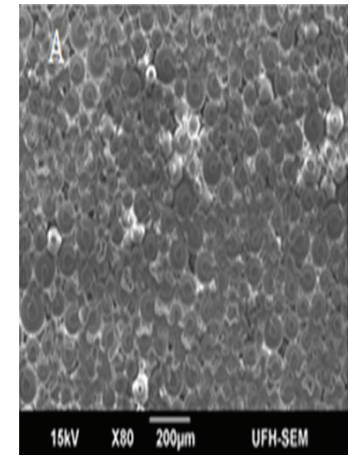

(A)

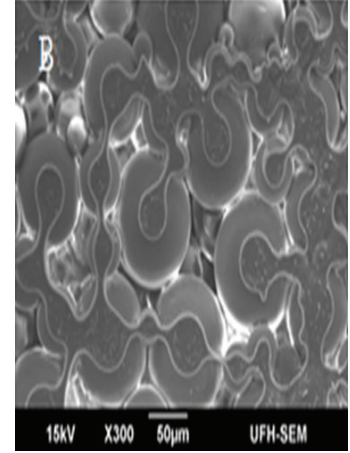

(B)

Full scale counts: $2498 \quad$ CdS2/PMMA(1)_pt1

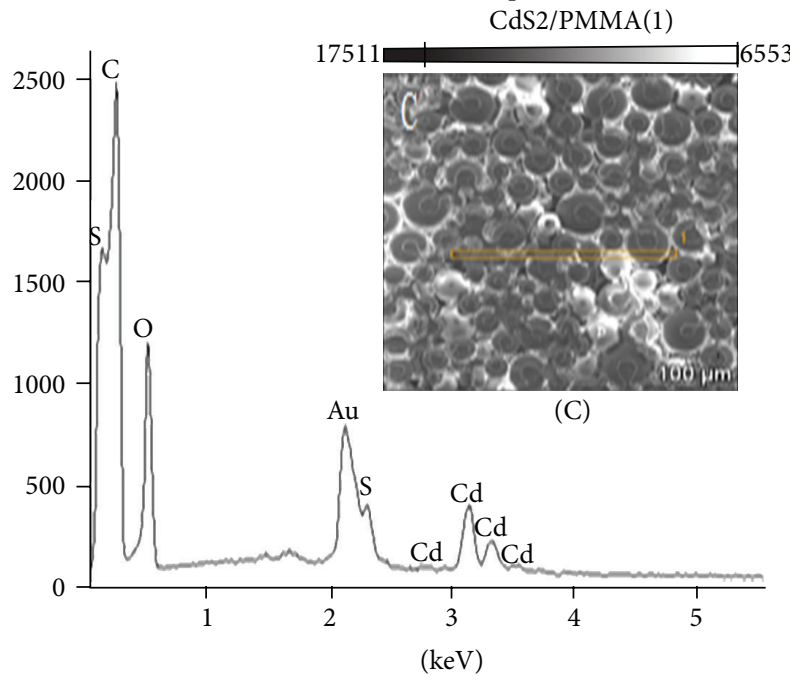

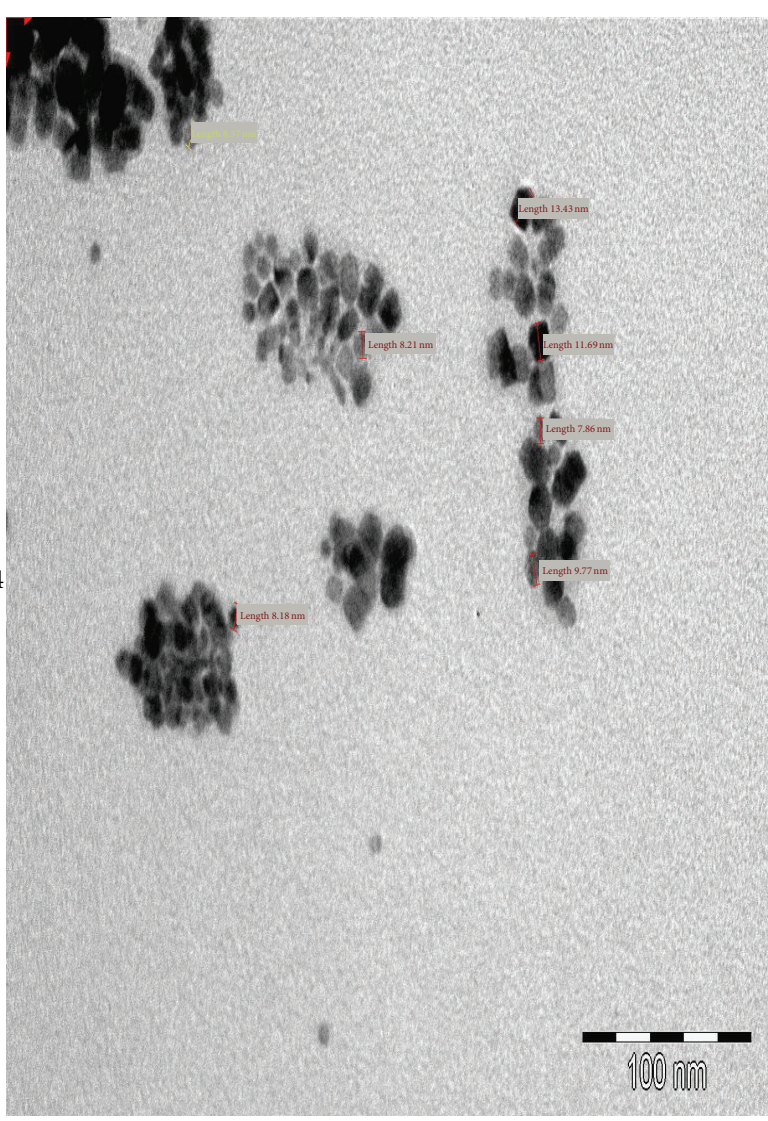

(D)

Figure 5: (A) and (B) are SEM micrograph of CdS2/PMMA nanocomposites at different magnification prepared from 3 wt.\% CdS2 nanoparticles dispersed in PMMA matrix. (C) EDX spectrum of the sample; (D) TEM micrograph.

in the PMMA matrix [36]. EDX spectrum of CdS/PMMA nanocomposites reveals that the prepared nanocomposites are mainly composed of cadmium and sulfur atoms within the scan area, confirming the presence of CdS nanoparticles in PMMA matrix. Other traces of elements like carbon and oxygen are observed possibly due to the use of carbon tape and retained solvent after the deposition step. The intense Au peaks are due to gold and palladium coating which was used to overcome charging of samples.

The surface morphology of the HgS/PMMA nanocomposites as shown in Figure 6(A) and 6(B). The pictures show evenly distributed spherical particles with agglomeration [23]. The EDX spectrum of the HgS/PMMA nanocomposites Figure $6(\mathrm{C})$ reveals that the prepared nanocomposites are mainly composed of $\mathrm{Hg}$ and $\mathrm{S}$, confirming the presence of $\mathrm{HgS}$ nanoparticles within the host PMMA matrix.

\subsection{TEM Images of Metal Sulfides/PMMA Nanocomposites.} The TEM image of ZnS/PMMA nanocomposites prepared from $\mathrm{ZnS}$ nanoparticles is shown in Figure 4(D). The TEM image showed the metal sulfide nanoparticles within the host PMMA matrices [37]. All the particles are within a narrow particle size range of 4.31-7.32 $\mathrm{nm}$ and small degree of agglomeration of nanocomposites is evident from the TEM image. The TEM image of CdS2/PMMA nanocomposites (Figure 5(D)) showed nanocomposites with an average size of about $10 \mathrm{~nm}$ with a standard deviation of less than $2.0 \mathrm{~nm}$. The nanocomposites showed mixture of cubic, hexagonal, and close-to-spherical particles that are similar to the TEM image of HDA-capped CdS2 nanoparticles. This similarity indicates that the shape of CdS2 nanoparticles is not affected by their dispersion in the polymer matrices. The polymer matrix holds the nanoparticles together and let them function as a unit. Lee et al. [30] reported similar results for CdS nanoparticles in thermotropic liquid crystal monomers.

The TEM micrograph of the HgS2/PMMA nanocomposites (Figure 6(D)) showed agglomerated particles that are in contact with each other. However most of the particles have irregular round shapes with relatively wide size distributions. The particles sizes are in the range of $8-20 \mathrm{~nm}$ which is in agreement with those reported $[38,39]$.

\section{Experimental Section}

3.1. Materials. Toluene was purchased from Aldrich. Poly(methyl methacrylate) PMMA was purchased from Aldrich. Toluene and PMMA were used as purchased, without further purification or modification. ZnS, CdS, 


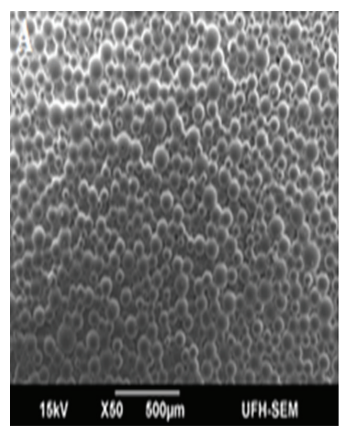

(A)

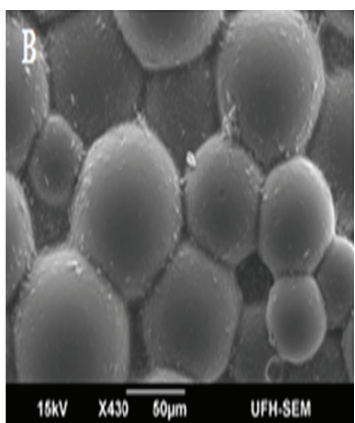

(B)

Full scale counts: $2987 \quad$ HgS2/PMMA(1)_pt1

HgS2PMMA(1)

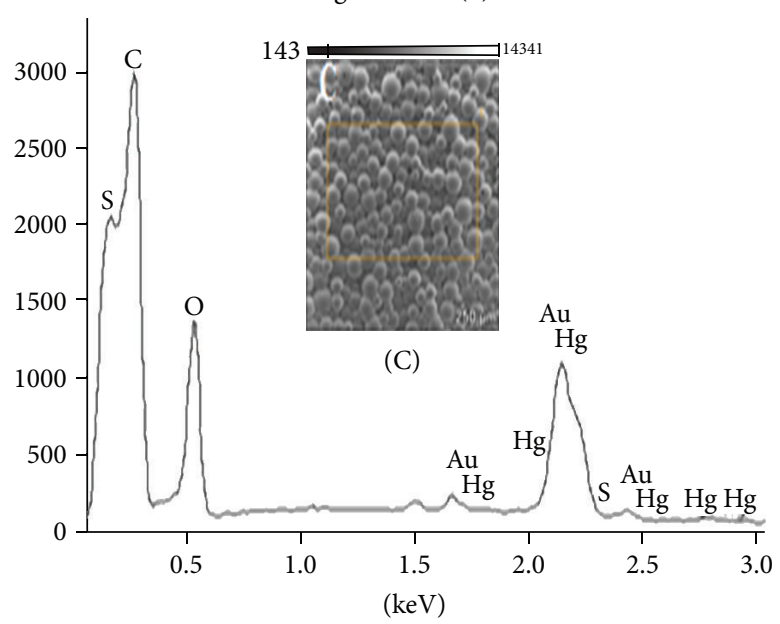

FIGURE 6: (A) and (B) are SEM micrograph of HgS2/PMMA nanocomposites. (C) EDX spectrum; (D) TEM image.

and HgS were prepared from the ( $N$-phenyl-N, N-methyl phenyl dithiocarbamate) $\mathrm{M}(\mathrm{II})$ complexes. $\mathrm{ZnS}$, CdS, and $\mathrm{HgS}$ nanoparticles were prepared from ( $N$-phenyl- $N, N$ ethylphenyldithiocarbamato)M(II) complexes [40].

3.2. Physical Measurements. Infrared spectra were recorded from $\mathrm{KBr}$ pellets in the range $4000-400 \mathrm{~cm}^{-1}$ on a Perkin Elmer 2000 FT-IR spectrometer. Powder X-ray diffraction patterns were recorded on Bruker-D8 ADVANCE powder $\mathrm{X}$-ray diffractometer instrument operating at a voltage of $40 \mathrm{kV}$ and a current of $30 \mathrm{~mA}$ with $\mathrm{Cu} \mathrm{K} \alpha$ radiation. Measurements were taken at a high angle $2 \theta$ range of $10-60^{\circ}$ using a scan speed of $0.01^{\circ}$, with filter time constant of $2.5 \mathrm{~s}$ per step and a slit width of $6.0 \mathrm{~mm}$. Thermogravimetric analyses experiments were carried out on a Perkin Elmer thermogravimetric analyser (TGA 7) fitted with a thermal analysis controller (TAC 7/DX). Samples of 10-20 mg of each complex were loaded into an alumina pan and weight changes were recorded as a function of temperature for a $10^{\circ} \mathrm{C} \mathrm{min} \mathrm{m}^{-1}$ temperature gradient between $20^{\circ} \mathrm{C}$ and $800^{\circ} \mathrm{C}$. A purge gas of flowing nitrogen at a rate of $20 \mathrm{~mL} \mathrm{~min}^{-1}$ was used.

The FTIR was done as $\mathrm{KBr}$ discs on a Perkin Elmer Paragon 2000 FTIR spectrophotometer in the range 4000$370 \mathrm{~cm}^{-1}$. The scanning electron microscopy (SEM) images were obtained in a Jeol, JSM-6390 LV apparatus, using an accelerating voltage between 15 and $20 \mathrm{kV}$ at different magnifications, as indicated in the SEM image. Energy dispersive spectra were processed using energy dispersive X-ray analysis (EDX) attached to a Jeol, JSM-6390 LV SEM with Noran System Six software. The accelerating voltage of $20.0 \mathrm{kV}$ and magnification of 1000 were used. The transmission electron microscopy (TEM) images were obtained using a ZEISS Libra 120 electron microscope operated at $120 \mathrm{kV}$. The samples were prepared by placing a drop of a solution of the sample in toluene on a carbon coated copper grid (300 mesh, agar). The excess solvent was wicked away with a paper tip and the samples were allowed to dry completely over night at room temperature. Images were recorded on a megaview G2 camera using iTEM Olympus software.

3.3. Synthesis of MS/PMMA Nanocomposites. The nanocomposites were prepared from their respective metal sulfide nanoparticles using modified methods reported by Prabhu and Pattabi [14] and Agrawal et al. [15]. In a typical experiment, $1.5 \mathrm{~g}$ of PMMA was dissolved in $20 \mathrm{~mL}$ toluene solution in a $100 \mathrm{~mL}$ glass beaker with the aid of magnetic stirrer for one hour. Another beaker solution containing 3.0\% (0.045 g) weight percent of $\mathrm{ZnS}$ nanoparticles dissolved in toluene was slowly added into the beaker containing the PMMA toluene solution with heating and vigorous stirring. The 
experiment continued for about 30 minutes. The resulting turbid solutions were poured on a Petri dish and allowed to dry in air. The other solution containing PMMA only was also prepared the same way. The same procedure was used for the synthesis of CdS/PMMA and HgS/PMMA nanocomposites. White or light yellow nanocomposites of $\mathrm{ZnS} / \mathrm{PMMA}$, CdS/PMMA, and HgS/PMMA were obtained in $85-95 \%$.

\section{Conclusions}

Metal sulfides nanoparticles/PMMA nanocomposites formulated as ZnS/PMMA, CdS/PMMA, and HgS/PMMA were synthesized from their metal sulfides nanoparticles in the presence of poly(methyl methacrylate) matrix. The metal sulfides/PMMA nanocomposites were characterized by infrared spectroscopy, thermal gravimetric analyses, SEM, EDX, and TEM. The FTIR spectra studies confirmed the dispersion of the metal sulfide nanoparticles into PMMA matrices. All the prepared nanocomposites showed reasonably good interactions between the metal sulfides nanoparticles and PMMA. The PMMA acted as good host matrix since it does not affect the shape and properties of the semiconductor metal sulfides nanoparticles dispersed in it but provided combinations of functionalities. The increasing order of particle sizes as calculated from the XRD is ZnS/PMMA < $\mathrm{HgS} / \mathrm{PMMA}<\mathrm{CdS} / \mathrm{PMMA}$ and ranges from 1.02 to $1.35 \mathrm{~nm}$. These calculated particle sizes are smaller than the values obtained from TEM which are $4-7 \mathrm{~nm}$ for $\mathrm{ZnS}, 10 \mathrm{~nm}$ for $\mathrm{CdS}$, and $8-20 \mathrm{~nm}$ for $\mathrm{HgS}$ nanoparticles in the PMMA matrices.

\section{Conflict of Interests}

The authors declare that there is no conflict of interests regarding the publication of this paper.

\section{Acknowledgment}

The authors acknowledge financial support of Govan Mbeki Research and Development Centre, University of Fort Hare.

\section{References}

[1] T. P. Mthethwa, M. J. Moloto, A. de Vries, and K. P. Matabola, "Properties of electrospun CdS and CdSe filled poly(methyl methacrylate) (PMMA) nanofibres," Materials Research Bulletin, vol. 46, no. 4, pp. 569-575, 2011.

[2] M. Dixit, S. Gupta, V. Mathur, K. S. Rathore, K. Sharma, and N. S. Saxena, "Study of glass transition temperature of PMMA and CdS-PMMA composite," Chalcogenide Letters, vol. 6, no. 3, pp. 131-136, 2009.

[3] S. Gross, D. Camozzo, V. Di Noto, L. Armelao, and E. Tondello, "PMMA: A key macromolecular component for dielectric low$K$ hybrid inorganic-organic polymer films," European Polymer Journal, vol. 43, no. 3, pp. 673-696, 2007.

[4] I.-Y. Jeon and J.-B. Baek, "Nanocomposites derived from polymers and inorganic nanoparticles," Materials, vol. 3, pp. 36543674, 2010.
[5] R. Chen, Y. Gao, G. Zhang, R. Wu, L. Xiao, and S. Jia, "Electric field induced fluorescence modulation of single molecules in PMMA based on electron transfer," International Journal of Molecular Sciences, vol. 13, no. 9, pp. 11130-11140, 2012.

[6] M. A. Uddin and H. P. Chan, "Materials and process optimization in the reliable fabrication of polymer photonic devices," Journal of Optoelectronics and Advanced Materials, vol. 10, no. 1, pp. 1-17, 2008.

[7] S. D. Alexandratos, "Ion-exchange resins: a retrospective from industrial and engineering chemistry research," Industrial and Engineering Chemistry Research, vol. 48, no. 1, pp. 388-398, 2009.

[8] S. B. Kondawar, S. A. Acharya, and S. R. Dhakate, "Microwave assisted hydrothermally synthesized nanostructure zinc oxide reinforced polyaniline nanocomposites," Advanced Materials Letters, vol. 2, no. 5, pp. 362-367, 2011.

[9] S. Ummartyotin, N. Bunnak, J. Juntaro, M. Sain, and H. Manuspiya, "Hybrid organic-inorganic of $\mathrm{ZnS}$ embedded PVP nanocomposite film for photoluminescent application," Comptes Rendus Physique, vol. 13, no. 9-10, pp. 994-1000, 2012.

[10] R. Zhao, C. Chen, Q. Li, and W. Luo, "Effects of stress and physical ageing on nonlinear creep behavior of poly(methyl methacrylate)," Journal of Central South University of Technology, vol. 15, no. 1, pp. 582-588, 2008.

[11] L. Zhang, F. Li, Y. Chen, and X. Wang, "Synthesis of transparent $\mathrm{ZnO} / \mathrm{PMMA}$ nanocomposite films through free-radical copolymerization of asymmetric zinc methacrylate acetate and in-situ thermal decomposition," Journal of Luminescence, vol. 131, no. 8, pp. 1701-1706, 2011.

[12] M. Salavati-Niasari and D. Ghanbari, "Polymeric nanocomposite materials," in Advances in Diverse Industrial Applications of Nanocomposites, B. Reddy, Ed., pp. 501-521, InTech, 2011, http://www.intechopen.com/books/advances-in-diverse-industrial-applications-ofnanocomposites/polymericnanocomposite-materials.

[13] A. Khan, "CdS nanoparticles with a thermoresponsive polymer: synthesis and properties," Journal of Nanomaterials, vol. 2012, Article ID 451506, 8 pages, 2012.

[14] S. G. Prabhu and B. M. Pattabi, "Incorporation of acetoacetanilide crystals in host PMMA polymer matrix and characterizations of the hybrid composite," Journal of Minerals and Materials Characterization and Engineering, vol. 11, pp. 519-527, 2012.

[15] S. Agrawal, D. Patidar, and N. S. Saxena, "Glass transition temperature and thermal stability of ZnS/PMMA nanocomposites," Phase Transitions, vol. 84, no. 11-12, pp. 888-900, 2011.

[16] L. Hashmi, P. Sana, M. M. Malik, A. H. Siddiqui, and M. S. Qureshi, "Novel fork architectures of $\mathrm{Ag}_{2} \mathrm{~S}$ nanoparticles synthesized through in-situ self-assembly inside chitosan matrix," Nano Hybrids, vol. 1, pp. 23-43, 2012.

[17] N. T. K. Thanh and L. A. W. Green, "Functionalisation of nanoparticles for biomedical applications," Nano Today, vol. 5, no. 3, pp. 213-230, 2010.

[18] A. A. Ezhov, G. A. Shandryuk, G. N. Bondarenko et al., "Liquidcrystalline polymer composites with CdS nanorods: Structure and optical properties," Langmuir, vol. 27, no. 21, pp. 1335313360, 2011.

[19] V. Pilla, L. P. Alves, E. Munin, and M. T. T. Pacheco, "Radiative quantum efficiency of CdSe/ZnS quantum dots suspended in different solvents," Optics Communications, vol. 280, no. 1, pp. 225-229, 2007. 
[20] A. Sabah, S. A. Siddiqi, and S. Ali, "Fabrication and characterization of CdS nanoparticles annealed by using different radiations," World Academy of Science, Engineering and Technology, vol. 70, pp. 82-89, 2010.

[21] J. Jang, S. Kim, and K. J. Lee, "Fabrication of CdS/PMMA core/shell nanoparticles by dispersion mediated interfacial polymerization," Chemical Communications, no. 26, pp. 26892691, 2007.

[22] S. Wei, J. Sampathi, Z. Guo et al., "Nanoporous poly(methyl methacrylate)-quantum dots nanocomposite fibers toward biomedical applications," Polymer, vol. 52, no. 25, pp. 5817-5829, 2011.

[23] B. Barman and K. C. Sarma, "Luminescence properties of ZnS quantum dots embedded in polymer matrix," Chalcogenide Letters, vol. 8, no. 3, pp. 171-176, 2011.

[24] L. F. Nicolais and G. Carotenuto, "Synthesis of polymerembedded metal, semimetal, or sulfide clusters by thermolysis of mercaptide molecules dissolved in polymers," Recent Patents on Materials Science, vol. 1, no. 1, pp. 1-11, 2008.

[25] K. Matras, M. Bredol, A. Szatkowski, O. Sakhno, J. Stumpe, and D. Bogdal, "Composites from luminescent nanosized $\mathrm{ZnS}$ and optical polymer," Molecular Crystals and Liquid Crystals, vol. 485, no. 1, pp. 776-779, 2008.

[26] A. K. Tomar, S. Mahendia, and S. Kumar, "Structural characterization of PMMA blended with chemically synthesized PAni," Advances in Applied Science Research, vol. 2, pp. 65-71, 2011.

[27] S. J. S. Qazi, A. R. Rennie, J. K. Cockcroft, and M. Vickers, "Use of wide-angle X-ray diffraction to measure shape and size of dispersed colloidal particles," Journal of Colloid and Interface Science, vol. 338, no. 1, pp. 105-110, 2009.

[28] Q. Chen, C. Suo, S. Zhang, and Y. Wang, "Effect of PdS on photocatalytic hydrogen evolution of nanostructured cds under visible light irradiation," International Journal of Photoenergy, vol. 2013, Article ID 149586, 5 pages, 2013.

[29] J. F. Luna-Martínez, D. B. Hernández-Uresti, M. E. ReyesMelo, C. A. Guerrero-Salazar, V. A. González-González, and S. Sepúlveda-Guzmán, "Synthesis and optical characterization of ZnS-sodium carboxymethyl cellulose nanocomposite films," Carbohydrate Polymers, vol. 84, no. 1, pp. 566-570, 2011.

[30] H. L. Lee, I. A. Mohammed, M. Belmahi, M. B. Assouar, H. Rinnert, and M. Alnot, "Thermal and optical properties of CdS nanoparticles in thermotropic liquid crystal monomers," Materials, vol. 3, no. 3, pp. 2069-2086, 2010.

[31] Z. Matusinovic, R. Shukla, E. Manias, C. G. Hogshead, and C. A. Wilkie, "Polystyrene/molybdenum disulfide and poly(methyl methacrylate)/molybdenum disulfide nanocomposites with enhanced thermal stability," Polymer Degradation and Stability, vol. 97, no. 12, pp. 2481-2486, 2012.

[32] W. Wichiansee, M. N. Nordin, M. Green, and R. J. Curry, "Synthesis and optical characterization of infra-red emitting mercury sulfide (HgS) quantum dots," Journal of Materials Chemistry, vol. 21, no. 20, pp. 7331-7336, 2011.

[33] S. K. Mehta, S. Kumar, S. Chaudhary, and K. K. Bhasin, "Nucleation and growth of surfactant-passivated CdS and HgS nanoparticles: time-dependent absorption and luminescence profiles," Nanoscale, vol. 2, no. 1, pp. 145-152, 2010.

[34] F. Oshal and H. Mossalayi, "Effect of matrices on size and morphology of HgS nanoparticle," Der Pharma Chemica, vol. 2, pp. 33-37, 2010.

[35] J. Kuljanin, M. Marinović-Cincović, Z. Stojanović, A. Krklješ, N. D. Abazović, and M. I. Comor, "Thermal degradation kinetics of polystyrene/cadmium sulfide composites," Polymer Degradation and Stability, vol. 94, pp. 891-897, 2009.

[36] C. K. Sheng, M. I. N. Isa, and L. H. Loo, "Study of formation and characterization of CdS/PMMA composite film," in Proceedings of the UMT 11th International Annual Symposium on Sustainability Science and Management, pp. 1080-1082, Terengganu, Malaysia, 2012.

[37] E. Mutlugun, P. L. Hernandez-Martinez, C. Eroglu et al., "Large-Area (over $50 \mathrm{~cm} \times 50 \mathrm{~cm}$ ) freestanding films of colloidal InP/ZnS quantum dots," Nano Letters, vol. 12, no. 8, pp. 39863993, 2012.

[38] P. S. Nair, T. Radhakrishnan, N. Revaprasadu, G. A. Kolawole, and P. O'Brien, "The synthesis of HgS nanoparticles in polystyrene matrix," Journal of Materials Chemistry, vol. 14, no. 4, pp. 581-584, 2004.

[39] F. Oshal and H. Mossalayi, "Effect of matrices on size and morphology of HgS nanoparticles," Der Pharma Chemica, vol. 2, pp. 33-37, 2010.

[40] J. Z. Mbese and P. A. Ajibade, "Synthesis, structural and optical properties of $\mathrm{ZnS}$, CdS and $\mathrm{HgS}$ nanoparticles from dithiocarbamato single molecule precursors," Journal of Sulfur Chemistry, vol. 35, no. 4, pp. 438-449, 2014. 

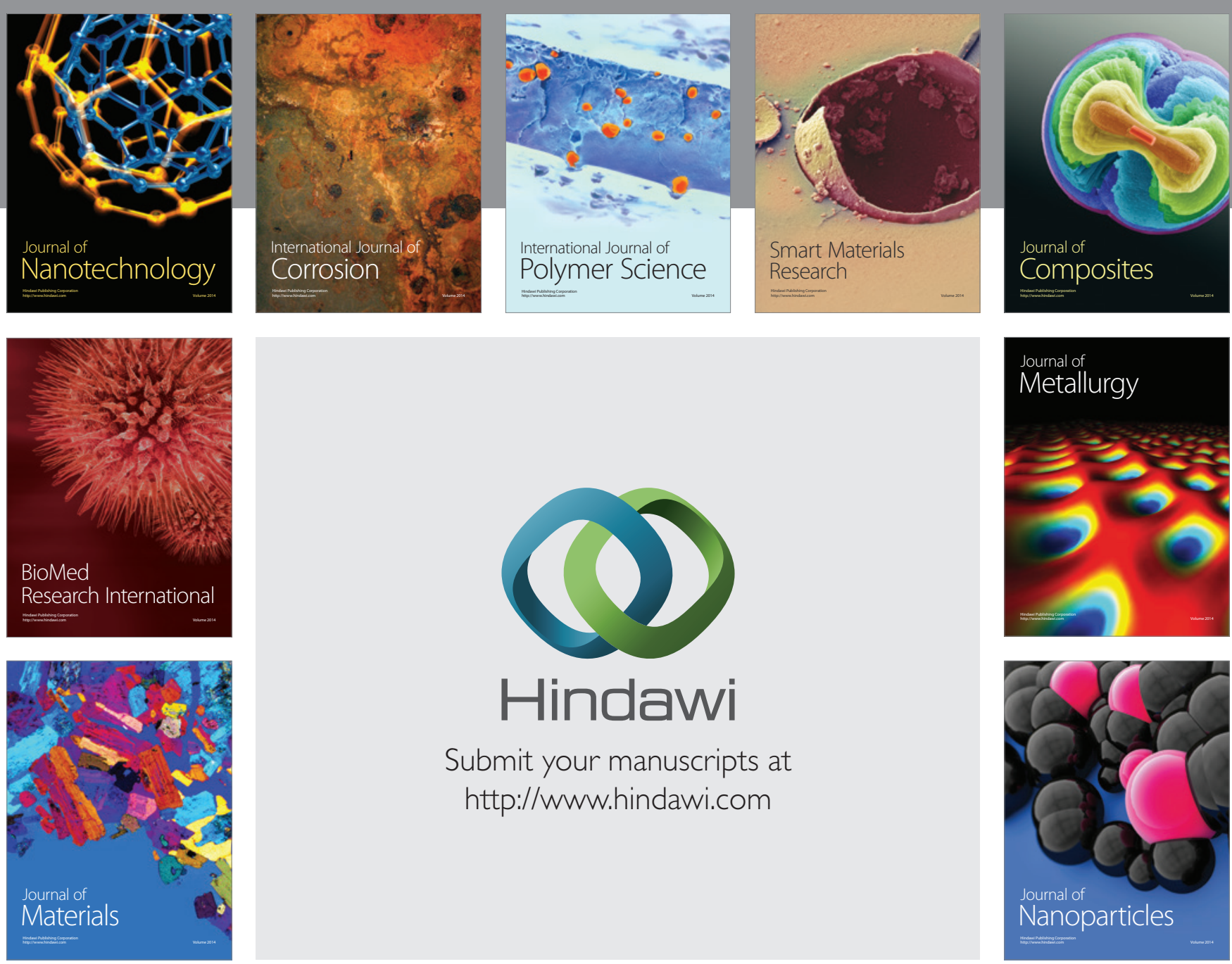

Submit your manuscripts at http://www.hindawi.com
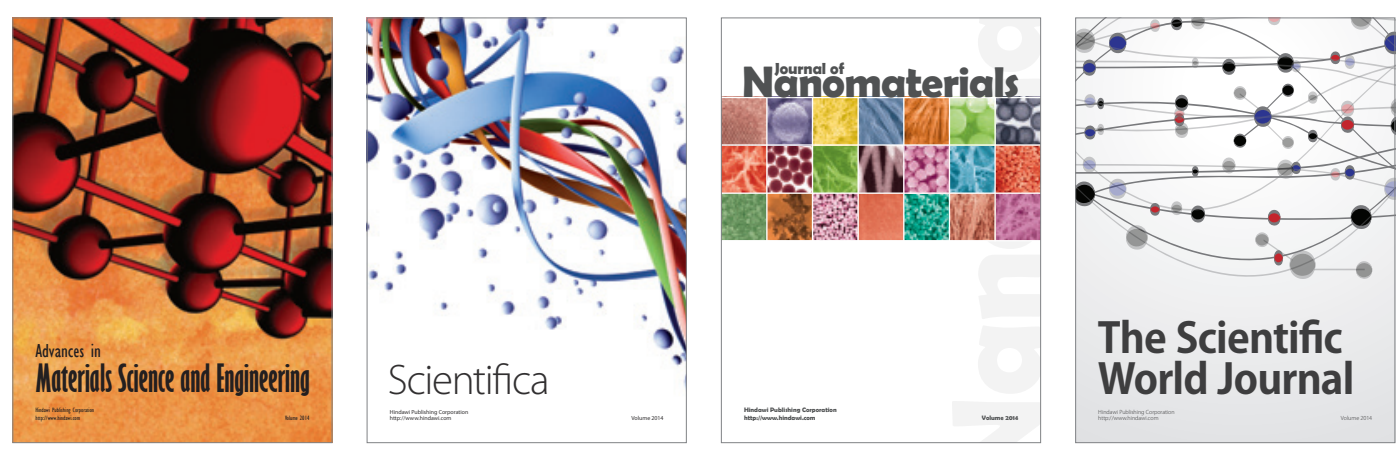

\section{The Scientific World Journal}
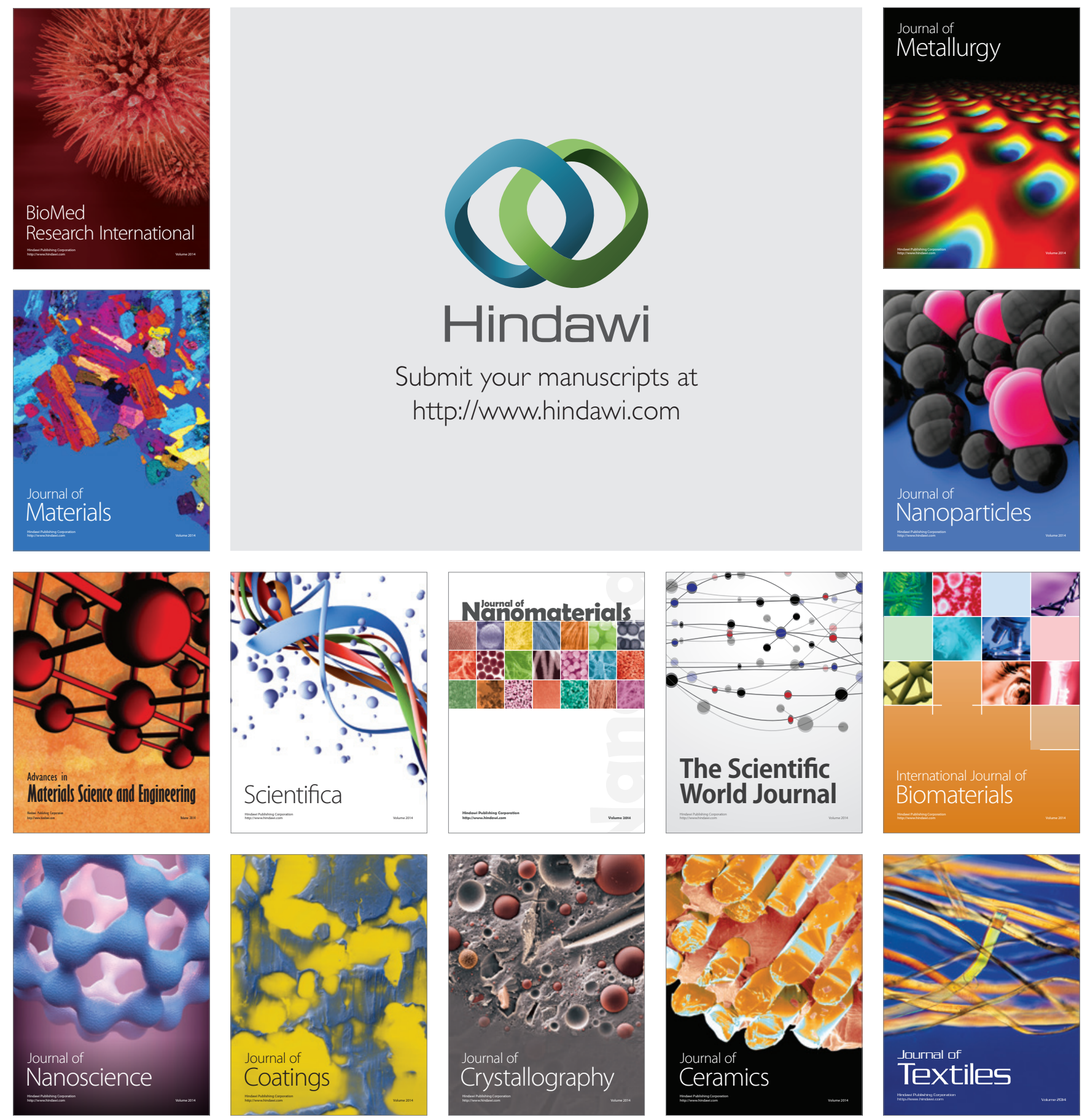